\title{
ASSESSMENT OF WORK-RELATED STRESS BY USING SALIVARY CORTISOL LEVEL EXAMINATION AMONG EARLY MORNING SHIFT WORKERS
}

\author{
Ol'ga Šušoliaková1, 2,4, Jindra Šmejkalová2 ${ }^{2}$ Marie Bičíková4, Lenka Hodačová3, Andrea Málková2, Zdeněk Fiala² \\ ${ }^{1}$ Department of Epidemiology and Public Health, Faculty of Medicine, University of Ostrava, Ostrava, Czech Republic \\ 2Department of Hygiene and Preventive Medicine, Faculty of Medicine in Hradec Králové, Charles University in Prague, Hradec Králové, Czech \\ Republic \\ ${ }^{3}$ Department of Social Medicine, Faculty of Medicine in Hradec Králové, Charles University in Prague, Hradec Králové, Czech Republic \\ ${ }^{4}$ Department of Steroid Hormones and Proteofactors, Institute of Endocrinology, Prague, Czech Republic
}

\begin{abstract}
SUMMARY
Objective: Early morning shifts have a negative effect on the hypothalamic-pituitary-adrenal axis. The aim of this study was to comprehensively assess the extent of occupational stress in early shift workers of the car industry by using salivary cortisol as an objective marker during a workday and on a day off.

Methods: For this cross-sectional epidemiological type of study, a survey included 55 suitable volunteers from the car industry. Five saliva samples were collected according to the following schedule: during one work day in the morning, during the morning shift from 6 a.m. -2 p.m., then after the shift was completed, 3 hours after work and in the evening before going to sleep. Control samples were taken from the same participants on a day off. Radioimmunoanalysis was used as the main analytical method, and the effect of factors and between-factor interactions on the levels of salivary cortisol during the workday were assessed using an ANOVA model.

Results: The cortisol diurnal rhythm was as expected, with the highest values in the morning and declining to the lowest values in the evening hours. Concentrations of salivary cortisol showed higher values during the workday, especially higher concentrations of evening cortisol and attenuated cortisol slope. Based on the results, irregular shift work has a greater increase in cortisol excretion after waking in the morning and a slower progressive recovery of the organism during the workday. In addition, cortisol levels were significantly higher in older women than in older men but did not differ in younger subjects.

Conclusions: Salivary cortisol levels are a suitable objective marker of stress and can be used as a good predictor of occupational stress by public health services for the purposes of primary prevention.
\end{abstract}

Key words: shift workers, occupational stress, work-related stress, salivary cortisol

Address for correspondence: 0 . Šušoliaková, National Institute of Public Health, Centre of Industrial Hygiene and Occupational Health, Šrobárova 48, 10042 Prague 10, Czech Republic. E-mail: olga.susoliakova@szu.cz

https://doi.org/10.21101/cejph.a5092

\section{INTRODUCTION}

In modern societies, more and more people work during "non-standard" working hours, including shift and night work, which are recognized risk factors for health, safety and social well-being. In recent years, many studies have reported troubles in psychological and social well-being, performance efficiency and increased stress levels (1). The arrangement of working hours has become a crucial factor in work organization and acquires different values according to the economic and social consequences that can arise at different periods of the company's and worker's life. Working hours have been extended to evening and night hours, as well as to the weekend, and hours of duty have become increasingly variable. Shift work (including night-shift work) may have various negative physiological and psychosocial effects that can affect health (2-5). Night work and rotating shift schedules interfere with the normal internal circadian rhythm and sleep-wake cycle (6). There are a variety of shift systems that differ greatly with respect to their structure. In this context, shift work is the most widely used tool of working time organization, as it enables round-the-clock activities not only in relation to rigid technological conditioning and necessary social services, but also to the support of productive and economic choices, as well as a wider use of leisure time (7). The most recent European statistics show that among various possible shift systems, alternating day (morning and afternoon) shifts are the most frequently used (8).

Normally, cortisol follows a robust circadian rhythm, with peak levels in the morning after waking, followed by decreasing levels throughout the day. More night-shift work, however, can lead to flattened cortisol profiles (9). Salivary cortisol is commonly used as a biomarker of psychosocial stress and related mental or psychological diseases, demonstrating activity of the hypothalamic-pituitary-adrenal (HPA) axis. Saliva collection is non-invasive and salivary biomarkers have the further advantage 
of being suitable for self-collection (10). Most previous studies of endocrine markers have focused on relationships of shift work and night work, and less is known about the effects of early-morning shift work. The main goal of this study was to analyze how the diurnal cortisol profile is affected during an early morning shift (measured by salivary cortisol), together with an assessment of organism recovery on a day off.

\section{MATERIALS AND METHODS}

\section{Procedure}

Our study consisted of 60 healthy shift workers in the car industry, but five participants were later excluded due to breaches of the study rules. Participants were informed of the study main goal, and a meeting with them was organized by the responsible person where they signed informed consent. All participants providing consent received basic instructions on how to work with a questionnaire and collect their own saliva according to a time schedule given. They were also informed of the main confounding factors, smoking status and their level of physical activity (mainly during work), which were recorded on a separate list. The following exclusion criteria were applied: psychiatric disorders, endocrine disorders such as diabetes mellitus, the presence of disease, and any allergy treated by corticoids. Women could not be pregnant. Salivette Cortisol Tubes (Sarstedt, Germany) were used for standardized saliva collection. Five saliva samples were obtained from each person according to the following schedule during one workday: first sample in the morning, followed by another sampling during the morning shift from 6 a.m. -2 p.m., then immediately after their shift, 3 hours after work and the last sample was collected in the evening before going to sleep. In the same group of participants, this time schedule of collection was also followed to collect control samples during a day off. After overall completion, samples were centrifuged and stored at $-80^{\circ} \mathrm{C}$. The concentration of salivary cortisol was measured by a radioimmunoassay method using a gamma counter (Berthold Company, Germany). Internal controls (low, medium and high) were included in the assay for analyzing follow-up accuracy.

\section{Data Management and Statistical Analysis}

The effect of factors and between-factor interactions on cortisol levels was assessed using an ANOVA model consisting of the following between-subject factors: Gender (men vs. women), Age ( $\leq 40$ years old vs. $>40$ years old), Physical Activity (low vs. high), Smoking Status (non-smokers vs. smokers), and the within-subject factor interactions Time and Gender $\times$ Age, Gender $\times$ Time, and Gender $\times$ Age $\times$ Time. The ANOVA model was followed by least significant difference multiple comparisons. Because of the skewed data distribution and non-constant variance in most dependent variables, these were transformed by power transformations to achieve data symmetry and homoscedasticity prior to further data processing (11). The homogeneity and distribution of the transformed data were checked by residual analysis as described elsewhere $(12,13)$. The statistical software Statgraphics Centurion, version XV from Statpoint Inc. (Herndon, Virginia, USA) was used for the ANOVA testing.

\section{RESULTS}

\section{Socio-demographic Data}

Our study group consisted of 33 women (60\%) and 22 men (40\%). The average age was $37 \pm 10$ years of age. Female shift workers were older (average age 38.2 \pm 9.2 years), compared to male shift workers (average age $35.4 \pm 10$ years). Using the age cut-off of 40 years, $61.8 \%$ of participants were younger (mean age $30.1 \pm 5.2$ years), compared to $38.1 \%$ of older participants (average age $48.3 \pm 5.2$ years). Most participants (56.4\%) had a high school education, $16.4 \%$ had a higher university degree, and the rest of participants $(27.3 \%)$ had not completed high school (Tables 1, 2 and 3).

Table 1. Description of demographic data according to gender, age, length of practice, and BMI

\begin{tabular}{|l|c|c|c|c|}
\hline \multirow{2}{*}{ Demographic variable } & \multicolumn{3}{|c|}{ Shift workers (N=55) } & \multirow{2}{*}{ p-value } \\
\cline { 2 - 5 } & All groups (N=55) & Women (N=33) & Men (N= 22) & \\
\cline { 2 - 4 } & Mean \pm SD & Mean \pm SD & $35.4 \pm 10.00$ & 0.348 \\
\hline Age & $37.0 \pm 10.27$ & $38.2 \pm 9.20$ & $7.09 \pm 6.68$ & 0.094 \\
\hline Length of practice & $9.14 \pm 7.70$ & $10.5 \pm 8.12$ & $26.39 \pm 3.29$ & 0.442 \\
\hline BMl & $25.91 \pm 3.98$ & $25.59 \pm 4.41$ & & \\
\hline
\end{tabular}

Table 2. Description of demographic data according to age groups

\begin{tabular}{|l|c|c|c|c|}
\hline \multirow{2}{*}{ Demographic variable } & \multicolumn{3}{|c|}{ Shift workers (N=55) } & \multirow{2}{*}{ p-value } \\
\cline { 2 - 4 } & All groups (N=55) & Younger $<40$ (N=34) & Older $\geq 40$ (N=21) & \\
\cline { 2 - 4 } & Mean \pm SD & Mean \pm SD & Mean \pm SD & $<0.001$ \\
\hline Length of practice & $9.14 \pm 7.70$ & $5.76 \pm 3.54$ & $14.61 \pm 9.40$ & $<0.01$ \\
\hline BMl & $25.91 \pm 3.98$ & $24.94 \pm 3.95$ & $27.49 \pm 3.59$ & $<$ \\
\hline
\end{tabular}


Table 3. Description of demographic data according to place of residence, educational level, and marital status

\begin{tabular}{|c|c|c|c|c|c|c|}
\hline \multirow{2}{*}{ Demographic variable } & \multicolumn{2}{|c|}{ Shift workers (N = 55) } & \multicolumn{2}{|c|}{ Women (N = 33) } & \multicolumn{2}{|c|}{ Men (N = 22) } \\
\hline & $\mathrm{n}$ & $\%$ & $\mathrm{n}$ & $\%$ & $\mathrm{n}$ & $\%$ \\
\hline \multicolumn{7}{|l|}{ Place of residence } \\
\hline City & 7 & 12.7 & 2 & 6.0 & 5 & 22.7 \\
\hline Town & 38 & 69.1 & 26 & 78.8 & 12 & 54.5 \\
\hline Village & 10 & 18.2 & 5 & 15.2 & 5 & 22.8 \\
\hline \multicolumn{7}{|l|}{ Educational level } \\
\hline Higher university degree & 9 & 16.4 & 13 & 39.4 & 2 & 9.1 \\
\hline High school education & 31 & 56.7 & 17 & 51.5 & 14 & 63.6 \\
\hline Vocational certificate & 15 & 26.9 & 3 & 9.1 & 6 & 27.3 \\
\hline \multicolumn{7}{|l|}{ Marital status } \\
\hline Married & 31 & 56.4 & 23 & 69.7 & 8 & 36.4 \\
\hline Single & 19 & 34.5 & 7 & 21.2 & 12 & 54.5 \\
\hline Divorced & 4 & 7.3 & 2 & 6.1 & 2 & 9.1 \\
\hline Widowed & 1 & 1.8 & 1 & 3.0 & 0 & 0.0 \\
\hline
\end{tabular}

\section{Salivary Cortisol Levels}

We found the highest peak of cortisol in the morning, followed by a decrease throughout the day to the lowest values around 10 p.m. to midnight (14). As shown in Figure 1, cortisol levels during the workday were higher in women compared with men,

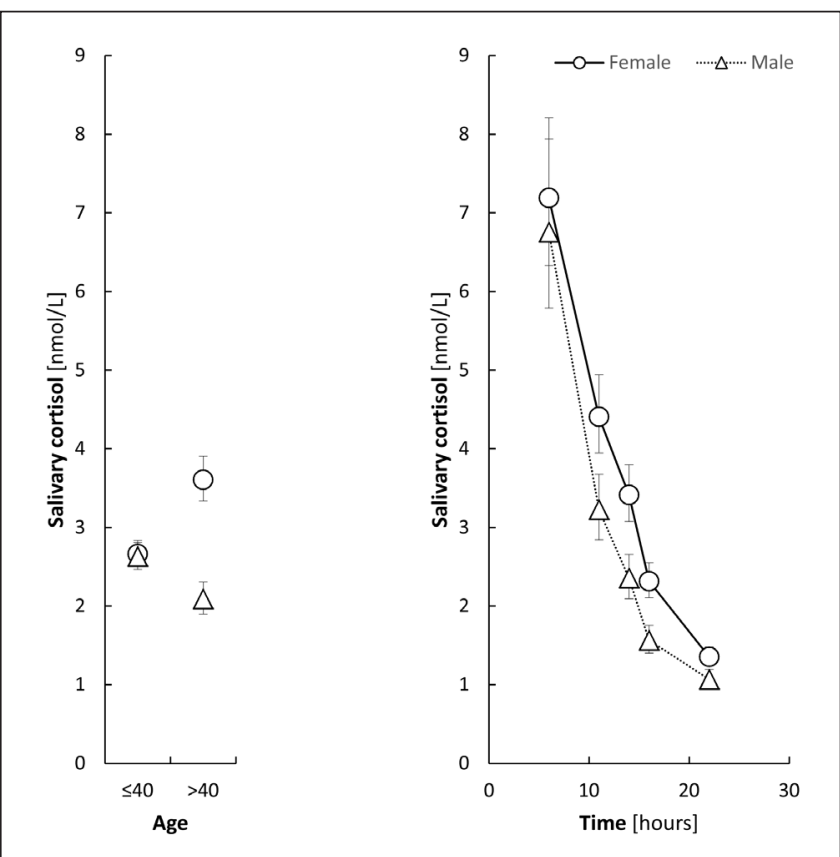

Fig. 1. Effect of factors and between-factor interactions on salivary cortisol levels during a workday.

The ANOVA model consists of a between subject factor, the subject factors Gender, Age, Physical Activity, Smoking Status, and the within-subject factor Time and Gender $\times$ Age, Gender $\times$ Time, and Gender $\times$ Age $\times$ Time interactions. Panel A illustrates the Gender $\times$ Age interaction: the circles and triangles with error bars represent group means with $95 \%$ confidence intervals for women and men, respectively, while Panel $B$ shows the Gender $\times$ Time interaction. The significances of factors and interaction were as follows: Gender: $F=31.2, p<0.001$; Age: $F=0.3, p=0.578$; Activity: $F=3.3$, $p=0.071$; Smoking: $F=0.1, p=0.746$; Time: $F=148.5, p<0.001$; Subject: $F=3.6$, $p<0.001 ;$ Gender $\times$ Age: $F=27.6, p<0.001 ;$ Gender $\times$ Time: $F=1.7, p=0.154 ;$ Gender $\times$ Age $\times$ Time: $F=2.1, p=0.085$

$p-p$-value, F - F statistic as the Gender factor was highly significant (Gender: $F=31.2$, $\mathrm{p}<0.001$ ), while the factor Age was insignificant. However, there was a highly significant Gender $\times$ Age interaction $($ Gender $\times$ Age: $\mathrm{F}=27.6, \mathrm{p}<0.001$ ), which means that there was a significantly different age relationship for men and women. The higher cortisol levels in women were only present in older participants $(\mathrm{p}<0.001$, least significant multiple comparisons), while they did not differ in younger men and women. In addition, the course of the diurnal rhythm did not significantly depend on gender, and the Physical

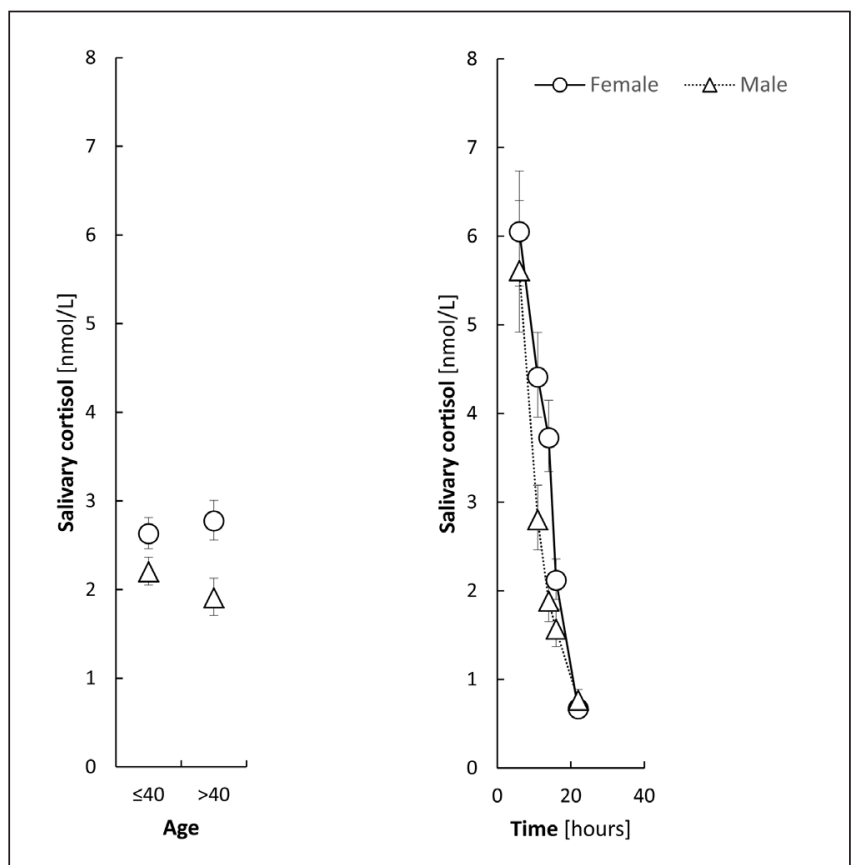

Fig. 2. Effect of factors and between-factor interactions on salivary cortisol levels on a day off.

ANOVA model - the significances of factors and interaction were as follows: Gender: $F=26.7, p<0.001 ;$ Age: $F=0.6, p=0.428 ;$ Activity: $F=2.1, p=0.151 ;$ Smoking: $F=1.9$, $p=0.174$; Time: $F=182.4, p<0.001$; Subject: $F=8, p<0.001$; Gender $\times$ Age: $F=3.3$, $p=0.071$; Gender $\times$ Time: $F=7.1, p<0.001$; Gender $\times$ Age $\times$ Time: $F=1.5, p=0.214$ The model, symbols and drawings are the same as for Figure 1. 


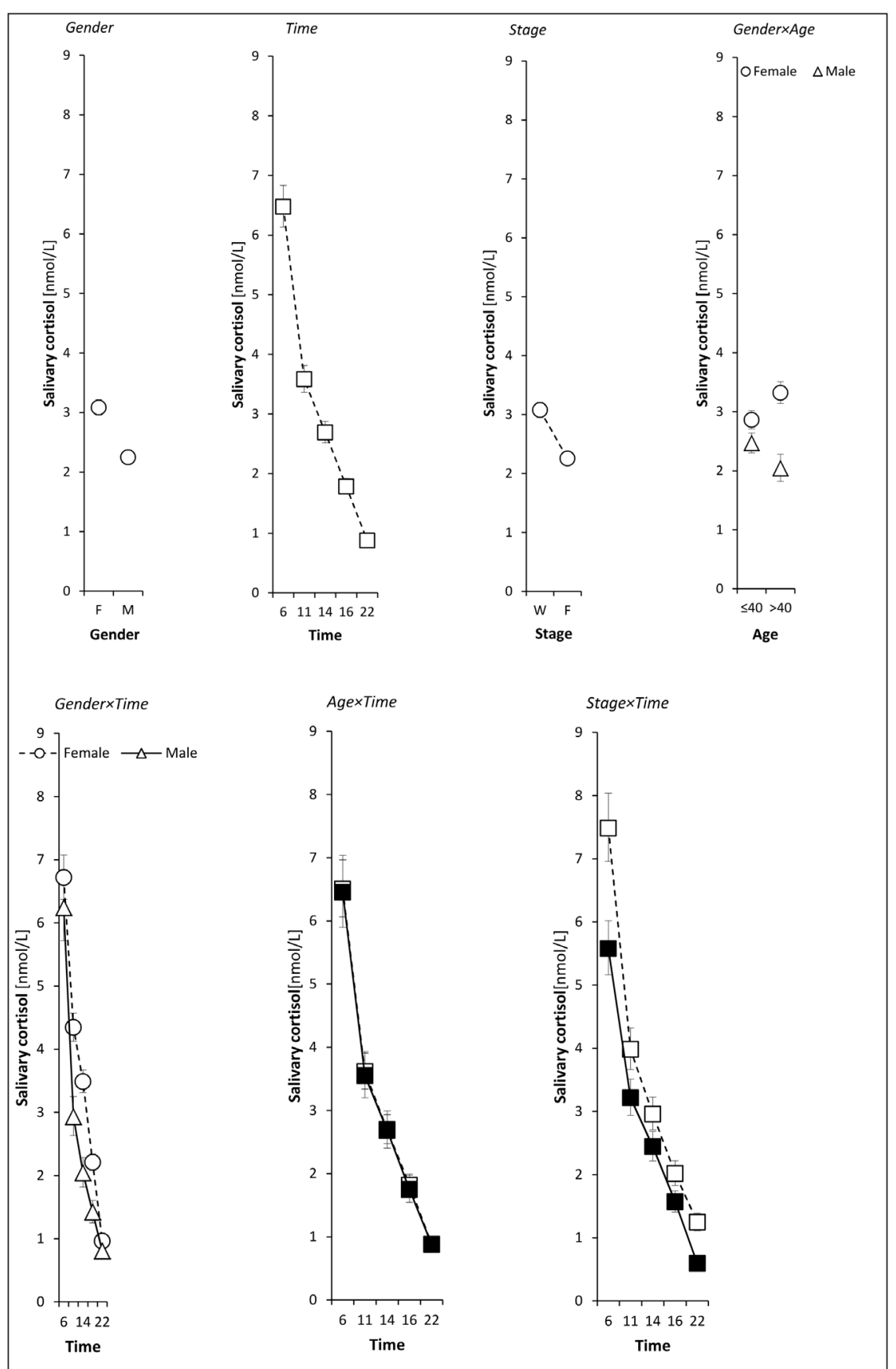

Fig. 3. Comparison of the effect of factors and between-factor interactions on salivary cortisol levels between the workday and the day off.

ANOVA model - the significances of factors and interaction were as follows: Gender: $F=37.7, p<0.001 ;$ Age: $F=0.1, p=0.812 ;$ Activity: $F=6.6, p=0.111 ;$ Smoking: $F=1.8$, $p=0.182$; Education: $F=1.3, p=0.278$; Stage: $F=55.2, p<0.001$; Time: $F=250.8, p<0.001$; Subject: $F=7.1, p<0.001 ; G e n d e r \times$ Age: $F=9.8, p=0.002 ;$ Gender $\times$ Stage: $F=0.7, p=0.39 ;$ Gender $\times$ Time: $F=4.4, p=0.002 ;$ Age $\times$ Stage: $F=7, p=0.009 ;$ Age $\times$ Time: $F=0, p=0.999 ;$ Stage $\times$ Time: $F=2.7, p=0.033 ;$ Gender $\times$ Age $\times$ Stage: $F=2.3, p=0.133$; Gender $\times$ Age $\times$ Time: $F=1.8, p=0.128 ;$ Age $\times$ Stage $\times$ Time: $F=0, p=0.999 ;$ Gender $\times$ Age $\times$ Stage $\times$ Time: $F=0.1, p=0.995$. The model, symbols and drawings are the same as for Figures 1 and 2 .

Activity factor and Smoking Status were also not significant. As expected, the within-subject factor Time, reflecting the diurnal cortisol rhythm, was highly significant. The inter-individual variability represented by the Subject factor was highly significant $(\mathrm{F}=3.6, \mathrm{p}<0.001)$ as well. As shown in Figure 2, cortisol levels on the day off were also higher in women than in men, as the Gender factor was highly significant $(F=26.7, p<0.001)$, while the Age, Physical Activity, and Smoking Status factors as well as the Gender $\times$ Age interaction were not significant. As in the case of workdays, there was a significantly different course of the diurnal rhythm (Gender $\times$ Time: $F=7.1, p<0.001)$ for women and men.

The inter-individual variability represented by the Subject factor was highly significant (Subject: $F=8.0, p<0.001$ ) as in the case of workdays.

As seen in Figure 3, the statistically different results of salivary cortisol levels between the workday and the day off were found mainly in the Gender factor, Time factor, Stage factor, Subject factor as well as the Gender $\times$ Age interaction, Gender $\times$ Time interaction, Age $\times$ Stage interaction and Stage $\times$ Time interaction. 


\section{DISCUSSION}

This study presents an assessment of occupational stress in shift workers, in particular in early morning shift workers of the car industry. One of the main reasons for choosing this group of workers is the fact that many previous endocrine studies were has been conducted in relation to work at night (15). However, the morning cortisol value has been described as a predictor of pathological states (16). Overall, the mean concentration of morning cortisol in our participants was $8.22 \mathrm{nmol} / 1$ during the workday, while the mean concentration during the day off reached $6.34 \mathrm{nmol} / \mathrm{l}$. When we took into account the influence of gender, female shift workers had a higher morning cortisol concentration (mean $8.40 \mathrm{nmol} / \mathrm{l}$ ) than male shift workers (mean $6.75 \mathrm{nmol} / \mathrm{l}$ ). These results are within the normal range for salivary cortisol in adults. Compared to other studies, however, our results are quite lower. The Swedish researchers Aardal and Holm found average values around $12 \mathrm{nmol} / 1$ in females and $10.7 \mathrm{nmol} / 1$ in males (17). Another Swedish study by Larsson et al. showed similar results (18), with a higher concentration of morning cortisol measured in 838 females (average levels around $12.15 \mathrm{nmol} / \mathrm{l}$ ) than in males (average levels around $11.1 \mathrm{nmol} / \mathrm{l}$ ). They also found no statistically significant differences between a workday and a day off. We might say that gender did not have any influence on the concentration of cortisol. Another study by Lundberg et al. focused on work related stress in working females demonstrated the reliability of morning cortisol as a valid indicator of physical overload and proposed using morning salivary cortisol as a tool for reducing work overload (19). The fact that the overall decline of morning cortisol levels from the workday to the day off is caused by eliminating the work overload was confirmed by Rydstedt et al. The decline was not very sharp, however, it indicated that factors other than just chronic stress are involved (20). Average evening cortisol levels for all participants were $1.48 \mathrm{nmol} / 1$ during the workday, declining to $0.75 \mathrm{nmol} / 1$ on the day off. Females had a mean concentration of $1.56 \mathrm{nmol} / 1$ and males had a mean concentration around 1.34 $\mathrm{nmol} / \mathrm{l}$ during the workday (a non-significant difference). But these values gradually decreased to a mean concentration of 0.76 $\mathrm{nmol} / \mathrm{l}$ in female shift workers and to a mean concentration of $0.75 \mathrm{nmol} / 1$ in male shift workers. This result was statistically significant $(\mathrm{p}<0.001)$. Based on the study by Rydstet et al., who assessed the influence of long-term chronic stress (especially in females), we conclude that this factor had a negative effect on evening cortisol levels (21).

According to Kunz-Ebrecht et al., higher cortisol levels on workdays than on days off have often been reported among daytime workers and have commonly been interpreted as an effect of anticipated workday stress (22). In a large study by Cohen et al., associations were reported between lower socioeconomic status and potentially higher evening salivary cortisol (23), indicating a need for greater recovery in those workers. In case of cortisol diurnal rhythm, Dahlgren et al. noted that in shift workers a diurnal slope of cortisol changed by fatigue and satiety can be observed (24). A study of British researchers (25) found that early morning shift workers had higher concentrations of cortisol, which was related to slower declining diurnal curves and greater hormonal output, as indicated by worse health (26). The main reasons were assumed to be: a lack of sleep, rising early and expected work stress. In our study, we did not take into account the quality or time of sleeping. Lower socioeconomic status may also be connected with a less marked slope (27). Taken together, we can say that shift work is characteristic of a lower socioeconomic status and decreased well-being. Depending on age, the group of younger participants ( $\leq 40$ years old) had lower cortisol concentrations throughout the day than their older colleagues ( $>40$ years), especially during the workday. Many studies have shown that elevated levels of cortisol in older participants may be due to physiological ageing and, according to some researchers, restrictions of serotonergic and cholinergic pathways as well (28). Cortisol values can also differ when comparing different occupations.

The study of Susoliakova et al. compared a group of 142 elementary school teachers and 136 male firefighters (29). Teachers' average concentrations of morning cortisol were around $7.9 \mathrm{nmol} / 1$ and evening cortisol $0.27 \mathrm{nmol} / 1$. The average values were lower for male firefighters (morning cortisol 5.64 $\mathrm{nmol} / \mathrm{l}$ and evening cortisol $0.18 \mathrm{nmol} / \mathrm{l}$ ). Their diurnal cortisol slope was also less pronounced, which is sign of worse health. The study of Perroni et al. concluded that the firefighters' daily work stressors were of a different intensity and that an adaptation to stress may play a role (30). Yang et al. assessed salivary cortisol in two groups of nurses - emergency department nurses and nurses from the general ward. Emergency department nurses showed elevated levels of stress compared to general ward nurses (31), and average levels of morning cortisol was significantly lower in emergency department nurses $(9.10 \mathrm{nmol} / \mathrm{l})$, compared to general ward nurses $(15.45 \mathrm{nmol} / \mathrm{l})$. Steroids have often been studied because salivary-free steroids hormones can give good information on serum-free levels (32). Testosterone, dehydroepiandrosterone (DHEA) could be a suitable example of other hormones with salivary cortisol.

\section{CONCLUSIONS}

The results of this study demonstrate that occupational stress can be assessed by salivary cortisol levels, especially using measurements including the day off after a workday. The study was limited by the rather low number of participants, and a more detailed examination of cortisol levels and the actual exposure to work-related stress would require a broader study.

For the purposes of primary prevention, the following recommendations should be considered:

- occupational stress should be regularly monitored;

- the possibility of non-work factors influencing work performance should be taken into account;

an extensive longitudinal study should be performed (ideally with a higher number of participants from different occupations);

in case of shift work, comparisons between morning, afternoon and night shifts should be taken into account.

\section{Acknowledgements}

This study was supported by the Faculty of Medicine in Hradec Králové, Charles University, Prague, Czech Republic (PROGRES Q40/09), and by the Ministry of Education, Youth and Sports of the Czech Republic (Specific university research project SVV No. SVV-260397/2017). 


\section{Adherence to Ethical Standards}

The study protocol was evaluated and subsequently approved by the Ethical Committee of the Institute of Endocrinology. The participants agreed to be part of the research.

\section{REFERENCES}

1. Costa G. The impact of shift and night work on health. Appl Ergon 1996;27(1):9-16.

2. Costa G. Factors influencing health of workers and tolerance to shift work. Theor Issues Ergon Sci. 2003;4(3-4):263-88.

3. Bjorvatn B, Keclund G, Åkerstedt T. Rapid adaptation to night work at an oil platform, but slow readaption after returning home. J Occup Environ Med. 1998;40(7):601-8

4. Åkerstedt T. Shift work and disturbed sleep / wakefulness. Occup Med (Lond). 2003;53(2):89-94.

5. Knutsson A. Health disorders on shift workers. Occup Med (Lond). 2003;53(2):103-8.

6. Weibel L, Spiegel K, Follenius M, Ehrhart J, Brandenberger G. Internal dissociations of the circadian markers of the cortisol rhythm in night workers. Am J Physiol. 1996;270(4 Pt 1):E608-13.

7. Costa G. The 24-hour society between myth and reality. J Hum Ergol. 2001;30(1-2):15-20.

8. Boisard P, Cartron D, Gollac M, Valeyre A. Time and work: duration of work. Dublin: European Foundation for the Improvement of Living and Working Conditions; 2003.

9. Lac G, Chamoux A. Biological and psychological responses to two rapid shiftwork schedules. Ergonomics. 2004;47(12):1339-49.

10. Šimůnková K, Stárka L, Dušková M, Hill M, Hampl R, Vondra K. Steroids in saliva: current application possibilities. Diabetol Metab Endokrinol Vyz. 2009;12(3):155-61. (In Czech.)

11. Meloun M, Hill M, Militky J, Kupka K. Transformation in the PC-aided biochemical data analysis. Clin Chem Lab Med. 2000;38(6):553-9.

12. Meloun M, Hill M, Militky J, Vrbikova J, Stanicka S, Skrha J. New methodology of influential point detection in regression model building for the prediction of metabolic clearance rate of glucose. Clin Chem Lab Med. 2004;42(3):311-22.

13. Meloun M, Militky J, Hill M, Brereton RG. Crucial problems in regression modelling and their solutions. Analyst. 2002;127(4):433-50.

14. Martin PA, Crump MH. The adrenal gland. In: Pineda MH, Dooley MP, editors. McDonald's veterinary endocrinology and reproduction. 5th ed. Ames: Iowa State University Press; 2002.

15. Karlson B, Carlsson Eek F, Hansen AM, Garde AH, Österberg K, Ørbæk P. Diurnal cortisol pattern of shift workers on a workday and a day off. Scand J Work Environ Health. 2006;32 Suppl 2:27-34.

16. Grossi G, Perski A, Ekstedt M, Johansson T, Lindström M, Holm K. The morning salivary cortisol response in burnout. J Psychosom Res. 2005;59(2):103-11.

17. Aardal E, Holm AC. Cortisol in saliva - reference ranges and relation to cortisol in serum. Eur J Clin Chem Clin Biochem. 1995;33(12):927-32.

18. Larsson CA, Gullberg B, Råstam L, Lindblad U. Salivary cortisol differs with age and sex and shows inverse associatons with WHR in Swedish women: a cross - sectional study. BMC Endocr Disord. 2009 Jun 21;9:16. doi: 10.1186/1472-6823-9-16.
19. Lundberg U, Hellström B. Workload and morning salivary cortisol in women. Work Stress. 2002;16(4):356-63.

20. Rydstedt LW, Cropley M, Devereux JJ, Michalianou G. The relationship between long term job strain and morning and evening saliva cortisol secretion among white-collar workers. J Occup Health Psychol. 2008;13(2):105-13.

21. Rydstedt LW, Cropley M, Devereux JJ, Michalianou G. The effects of gender, long-term need for recovery and trait inhibition-rumination on morning and evening saliva cortisol secretion. Anxiety Stress Coping. 2009;22(4):465-74.

22. Kunz-Ebrecht SR, Kirschbaum C, Steptoe A. Work stress, socioeconomic status, and neuroendocrine activation over the working day. Soc Sci Med. 2004;58(8):1523-30.

23. Cohen S, Schwartz JE, Epel E, Kirschbaum C, Sidney S, Seeman T. Socioeconomic status, race and diurnal cortisol decline in the Coronary Artery Risk Development in Young Adults (CARDIA) Study. Psychosom Med. 2006;68(1):41-50.

24. Dahlgren A, Kecklund G, Theorell T, Åkerstedt T. Day-to-day variation in saliva cortisol - relation with sleep, stress and self-rated health. Biol Psychol. 2009;82(2):149-55.

25. Bostock S, Steptoe A. Influences of early shift work on the diurnal cortiso rhythm, mood and sleep: Within-subject variation in male airline pilots. Psychoneuroendocrinology. 2013;38(4):533-41.

26. Hagger-Johnson GE, Whiteman MC, Wawrzyniak AJ, Holroyd WG. The SF-36 component summary scales and the daytime diurnal cortisol profile. Qual Life Res. 2010;19(5):643-51

27. Brandtstädter J, Baltes-Götz B, Kirschbaum C, Hellhammer D. Developmental and personality correlates of adrenocortical activity as indexed by salivary cortisol: observations in the age range of 35 to 65 years. J Psychosom Res. 1991;35(2-3):173-85.

28. Ferrari E, Cravello L, Muzzoni B, Casarotti D, Paltro M, Solerte SB, et al. Age-related changes of the hypothalamic-pituitary - adrenal axis: pathophysiological correlates. Eur J Endocrinol. 2001;144(4):319-29.

29. Susoliakova O, Smejkalova J, Bicikova M, Potuznikova D, Hodacova L, Grimby-Ekman A, et al. Salivary cortisol in two professions: daily cortisol profiles in school teachers and firefighters. Neuro Endocrinol Lett. 2014;35(4):314-21.

30. Perroni F, Tessitore A, Cibelli G, Lupo C, D'Artibale E, Cortis C, et al. Effects of simulated firefighting on the responses of salivary cortisol, alpha amylase and psychological variables. Ergonomics. 2009;52(4):484-91.

31. Yang Y, Koh D, Ng V, Lee FCY, Chan G, Dong F, et al. Salivary cortiso levels and work-related stress among emergency department nurses. J Occup Environ Medicine. 2001;43(12):1011-8.

32. Kumar AM, Solano MP, Fernandez JB, Kumar M. Adrenocortical response to ovine corticotropin - releasing hormone in young men: cortisol measurements in matched samples of saliva and plasma. Horm Res. 2005;64(2):55-60. 